\title{
Improving Acquisition of Phosphorus and Other Nutrient Elements by Baby Corn (Zea mays L.) through the Combine Use of Biochar, Phosphorus and Arbuscular Mycorrhiza
}

\author{
Arghya Chattopadhyay ${ }^{1 *}$, A.P. Singh ${ }^{1}$, Sumit Rai ${ }^{1}$, Awtar Singh ${ }^{1}$ and Ajoy Das ${ }^{2}$ \\ ${ }^{1}$ Department of Soil Science and Agricultural Chemistry, Banaras Hindu University, \\ Varanasi- 221 005, India \\ ${ }^{2}$ Department of Agronomy, Bidhan Chandra Krishi Viswavidyalaya, Mohanpur- 741 252, India \\ *Corresponding author
}

A B S T R A C T

Keywords

Baby corn, Biochar, Mycorrhiza and Phosphorus.

Article Info

Accepted:

12 September 2017

Available Online:

10 November 2017
A pot experiment was conducted in the Department of Soil Science and Agricultural Chemistry, Institute of Agricultural Sciences Banaras Hindu University, Varanasi, India during kharif season of 2015 to investigate the effect of biochar, phosphorus and mycorrhiza on performance of baby corn and its quality. The treatments included two levels of phosphorus viz. P @ 50\% RDF and no P along with full dose of nitrogen and potassium and four levels of biochar. Biochars used were prepared from rice husk, lantana and parthenium each applied @ $4.545 \mathrm{~g} \mathrm{~kg}^{-1}$ soil. Two levels of mycorrhiza (inoculated and uninoculated) were also included in the treatments. Investigation indicates that valuable effects of biochar could be obtained if it was applied with mycorrhiza. Combined application of biochar (10 $\mathrm{t} \mathrm{ha}^{-1}$ soil), phosphorus along with mycorrhiza produced significantly higher uptake of nutrients in baby corn. Biochars are highly variable in nutrient composition and availability, which are determined by types of feedstock and pyrolysis conditions. The results suggest that high-ash biochars with phosphorus are potential $\mathrm{P}$ sources with high-agronomic efficiency.

\section{Introduction}

For achieving high yields farmers are compelled to adopt different types of management practices like intensive cultivation and enhanced use of agrochemicals mainly fertilizers and pesticides that cause remarkable change in the environment and under many condition leading to deterioration of soil quality and decline in soil organic carbon at different places of India. Therefore, the task of attaining higher productivity of crops and maintaining soil quality at the same time could be achieved by integrating new approaches that involve use of low cost organic soil amendments, conditioners. One such sustainable technology is application of biochar. Biochar can enhance growth of plants and improve physical, chemical and biological properties of soil.

Presently, in Europeans countries use of biocharas a soil amendment is going on a large scale, but in India biochar has not been adopted so extensively. 


\section{Materials and Methods}

\section{Study area}

The experiment was conducted during kharif season of 2015 in net house of the Department of Soil Science and Agricultural Chemistry, Institute of Agricultural Sciences, Banaras Hindu University, Varanasi, India.

Statistical analysis was done in factorial completely randomized design with 16 treatment combinations replicated thrice other relevant details are given here under.

\section{Experimental soil}

Bulk soil sample $(0-15 \mathrm{~cm})$ was collected from Research Farm of the Institute of Agricultural Sciences, Banaras Hindu University. Varanasi, India. It was ground and passed through $2.0 \mathrm{~mm}$ sieve and $10 \mathrm{~kg}$ of pressed soil was filled in each polythene lined pot. Five seeds of maize (variety MalviyaMakka 2) were transplanted in each pot and soil in each pot was pulverized manually.

Four plants were maintained after establishment. The pots were irrigated as per need.

The soil used for experimentation was sandy loam with bulk density $1.63 \mathrm{Mgm}^{-3}, \mathrm{pH}$ (1:2.5) 7.6, E.C. $0.21 \mathrm{dsm}^{-1}$, CEC 11.63 cmol $\left(\mathrm{p}^{+}\right) \mathrm{kg}^{-1}$, organic carbon $0.34 \%$, available $\mathrm{N} 135 \mathrm{~kg} \mathrm{ha}^{-1}$, available P $22.7 \mathrm{~kg}$ $\mathrm{ha}^{-1}$ and available K $183 \mathrm{~kg} \mathrm{ha}^{-1}$.

\section{Source of biochar and arbuscular mycorrhiza}

Arbuscular mycorrhiza and biochar were obtained from the Department of Soil Science and Agricultural Chemistry, Institute of Agricultural Sciences, Banaras Hindu University, Varanasi, U.P. (India).

\section{Fertilizer application}

Phosphorus having two levels viz. no P (P0) and P @ 50\% RDF (P1) along with full dose of nitrogen and potassium were applied. Required quantities of fertilizers for each pot (10 kg soil) were calculated and applied in solution form using urea, $\mathrm{KH}_{2} \mathrm{PO}_{4}$ and $\mathrm{KCl}$ as source of N, P, and K respectively. So rates of $\mathrm{N}, \mathrm{P}$ and $\mathrm{K}$ for each pot (10 kg soil) were 0.66 $\mathrm{g}, \quad 0.13 \mathrm{~g}$ and $0.17 \mathrm{~g}$ respectively corresponding to 150,30 and $40 \mathrm{~kg} \mathrm{ha}^{-1}$. Half the dose of $\mathrm{N}$ was applied as basal and left over amount was added in two split at 30 and 45 days after sowing. Full dose of $\mathrm{P}_{2} \mathrm{O}_{5}$ was applied as $\mathrm{KH}_{2} \mathrm{PO}_{4}$ in all the 24 pots and it met the $\mathrm{K}_{2} \mathrm{O}$ requirement of the crop as it contained $35 \% \mathrm{~K}_{2} \mathrm{O}$.

\section{Biochar application}

Three types of biochar viz. rice husk biochar $(\mathrm{RBH})$, lantana biochar (LB), and partheniumbiochar (PB) were applied corresponding $10 \mathrm{t} \mathrm{ha}^{-1}$ and one treatment (NB) did not supply any. Required quantities of biochar for $10 \mathrm{~kg}$ soil were calculated and the full dose was applied as soil application before sowing the maize seeds.

\section{Arbuscular mycorrhiza application}

Mycorrhizal treatment had two levels i.e., with mycorrhiza (AM1) and without mycorrhiza (AM0). Mycorrhizal consortia were applied @ $5 \mathrm{~g} \mathrm{pot}^{-1}$ by spreading over the moist top soil of the pots followed by covering with thin $(2-3 \mathrm{~cm})$ soil layer.

\section{Sampling and analysis}

Plant samples after harvesting were dried at $65-70^{\circ} \mathrm{C}$ and nitrogen, phosphorus, and potassium were analyzed following suitable methods as mentioned in the practical manual of Tandon (2001). 


\section{Results and Discussion}

Phosphorus uptake by cob and straw of baby corn

Effect of application of phosphorus, biochar and mycorrhizal inoculation on phosphorus uptake in cob and straw of baby corn varied significantly (Table 1). Application of P1 in soil increased significantly phosphorus uptake by cob and straw and the values exceed by $35.7 \%$ and $35.0 \%$ over P0. Application of biochar had a significant effect on phosphorus uptake of cob compared to NB. Application of LB showed significantly higher phosphorus uptake in cob and straw and recorded increments were $9.88 \%$ and $2.51 \%$ respectively compared to NB.

The increased uptake of phosphorus in cob was happening due to the fact that biochar contained remarkable amount of phosphorus. The inoculation with mycorrhiza increased the phosphorus uptake in cob and straw by $24.1 \%$ and $14.5 \%$, respectively over AM0. It was probably due to secretion of phosphatase enzyme by mycorrhiza which solubilized inorganic phosphorus and there by increased phosphorous uptake.

Significant interaction between phosphorus and biochar was observed for phosphorus uptake in cob and straw. The application of $\mathrm{LB}+\mathrm{P} 1$ showed higher phosphorus uptake in cob $\left(50.1 \mathrm{mg} \mathrm{pot}^{-1}\right)$ and straw $\left(30.0 \mathrm{~g} \mathrm{pot}^{-1}\right)$ over the pots which did not receive any biochar and phosphorus. Significant interaction between phosphorus and mycorrhiza was observed for phosphorus uptake in cob. The application of P1+AM1 showed higher phosphorus uptake in cob $\left(52.8 \mathrm{mg} \mathrm{pot}^{-1}\right)$ over P0+AM0 (31.5 mg pot $\left.{ }^{-1}\right)$. Significant interaction between biochar and mycorrhiza was observed for phosphorus uptake in cob. The application of LB+AM1 showed higher phosphorus uptake in cob
(48.4 mg pot ${ }^{-1}$ ) over NB+AM0 (34.7 mg pot $\left.{ }^{1}\right)$.

Arbuscular mycorrhizal fungi hyphae normally transport $\mathrm{P}$ located at greater distances from the root than do non mycorrhizal roots (Tinker et al., 1992). Interaction effect among of phosphorus, mycorrhiza and biochar was found to increase significantly the phosphorus uptake of baby corn. The application of LB+P1+AM1 showed higher phosphorus uptake in cob $\left(57.1 \mathrm{mg} \mathrm{pot}^{-1}\right)$ over NB+P0+AM0 $(30.0 \mathrm{mg}$ pot $\left.^{-1}\right)$. Greater resin-extractable $\mathrm{P}$ from bone char produced at $350^{\circ} \mathrm{C}$ in comparison to unpyrolyzed bone meal additions to soil was explained by the increase in hydroxyl apatitelike crystals through pyrolysis, which reduces water-extractable $\mathrm{P}$ but increases formic extractable $\mathrm{P}$ representing plant-available $\mathrm{P}$ (Zwetsloot et al., 2016).

Nitrogen uptake by cob and straw of baby corn

Application of AM1 showed significantly higher nitrogen uptake of cob and straw of baby corn and the increments were $4.05 \%$ and $4.65 \%$, respectively over AM0. Effect of application of biochar was found to be nonsignificant on nitrogen uptake of cob and straw. The application of P1 showed significantly higher nitrogen uptake in cob and straw, the increments being $23.8 \%$ and $15.4 \%$ respectively over P0.Significant interaction between phosphorus and biochar was observed for nitrogen uptake by cob and straw. The highest uptake of nitrogen by cob (174 $\mathrm{mg} \mathrm{pot}^{-1}$ ) was obtained with the application of LB+P1. Straw nutrient uptake recorded highest uptake of nitrogen $(3.84 \mathrm{~g}$ pot $^{-1}$ ) when PB and P1 were applied in combination. Arbuscular mycorrhiza and biochar interaction was also significant for nitrogen uptake in cob and straw. The highest uptake of nitrogen in cob was obtained with 
the application of LB+AM1 (160 mg $\left.\operatorname{pot}^{-1}\right)$. Straw recorded highest uptake of nitrogen (3.7 $\mathrm{g} \mathrm{pot}^{-1}$ ) using combined application of $\mathrm{PB}$ and AM1.

Ammonium-N acquisition by arbuscular mycorrhizal treated plants has been considered more important than $\mathrm{NO}_{3}-\mathrm{N}$ because of the lower mobility of $\mathrm{NH}_{4}-\mathrm{N}$ in soil compared to $\mathrm{NO}_{3}-\mathrm{N}$ (Marschner and Dell, 1994), although acquisition and hyphal transport of both forms of $\mathrm{N}$ may readily occur in arbuscular mycorrhizal fungi treated plants (Subramanian and Charest, 1998).
Arbuscular mycorrhizal fungi hyphae have the capacity to take up and transport $\mathrm{N}$ from soil to roots (Bago et al., 1996).Interaction among phosphorus, biochar and arbuscular mycorrhizal application was significant for nitrogen uptake of coband combined application of phosphorus, lantana biochar and arbuscular mycorrhizal application gave nitrogen uptake to the magnitude of $180 \mathrm{mg}$ pot $^{-1}$ compared with uptake of $137 \mathrm{mg} \mathrm{pot}^{-1}$ with control. George et al., (1992) reported that $30-40 \%$ of $\mathrm{N}$ in arbuscular mycorrhizal treated plants may be contributed by hyphae.

Table.1 Nitrogen, phosphorus and potassium uptake by cob and straw of baby corn as affected by different levels of phosphorus, biochar and AM

\begin{tabular}{|c|c|c|c|c|c|c|}
\hline \multirow[t]{2}{*}{ Treatment } & \multicolumn{2}{|c|}{ Nitrogen uptake } & \multicolumn{2}{|c|}{ Phosphorus uptake } & \multicolumn{2}{|c|}{ Potassium uptake } \\
\hline & $\begin{array}{c}\text { Cob } \\
\left(\mathrm{mg} \mathrm{pot}^{-1}\right)\end{array}$ & $\begin{array}{c}\text { Straw } \\
\left(\mathrm{g} \mathrm{pot}^{-1}\right)\end{array}$ & $\begin{array}{c}\text { Cob } \\
\left(\mathrm{mg} \mathrm{pot}^{-1}\right)\end{array}$ & $\begin{array}{c}\text { Straw } \\
\left(\text { g pot }^{-1}\right)\end{array}$ & $\begin{array}{c}\text { Cob } \\
\left(\mathrm{mg} \mathrm{pot}^{-1}\right)\end{array}$ & $\begin{array}{c}\text { Straw } \\
\left(\text { g pot }^{-1}\right)\end{array}$ \\
\hline NB & 154 & 3.37 & 39.2 & 0.77 & 54.0 & 4.24 \\
\hline RHB & 155 & 3.54 & 41.3 & 0.83 & 54.6 & 4.48 \\
\hline PB & 153 & 3.63 & 41.8 & 0.85 & 54.5 & 4.60 \\
\hline LB & 155 & 3.63 & 43.0 & 0.87 & 55.9 & 4.60 \\
\hline SEm \pm & 0.87 & 0.01 & 0.32 & 0.01 & 0.32 & 0.02 \\
\hline $\mathrm{CD}(\mathbf{p} \leq \mathbf{0 . 0 5})$ & 2.50 & 0.04 & 0.94 & 0.03 & 0.93 & 0.04 \\
\hline $\mathbf{P 0}$ & 138 & 3.29 & 35.0 & 0.71 & 48.7 & 4.19 \\
\hline P1 & 171 & 3.79 & 47.5 & 0.95 & 60.8 & 4.77 \\
\hline SEm \pm & 0.61 & 0.01 & 0.23 & 0.01 & 0.23 & 0.01 \\
\hline $\mathrm{CD}(\mathbf{p} \leq \mathbf{0 . 0 5})$ & 1.77 & 0.03 & 0.66 & 0.02 & 0.66 & 0.03 \\
\hline AM0 & 152 & 3.46 & 36.8 & 0.77 & 53.1 & 4.36 \\
\hline AM1 & 157 & 3.62 & 45.7 & 0.89 & 56.4 & 4.61 \\
\hline SEm \pm & 0.61 & 0.01 & 0.23 & 0.01 & 0.23 & 0.01 \\
\hline $\mathrm{CD}(\mathbf{p} \leq \mathbf{0 . 0 5})$ & 1.77 & 0.03 & 0.66 & 0.02 & 0.66 & 0.03 \\
\hline $\mathbf{P} \times \mathbf{B}$ & $\mathrm{S}$ & $\mathrm{S}$ & $\mathrm{S}$ & $\mathrm{S}$ & $\mathrm{S}$ & $\mathrm{S}$ \\
\hline $\mathbf{P} \times \mathbf{A M}$ & NS & NS & S & NS & S & S \\
\hline $\mathbf{B} \times \mathbf{A M}$ & $\mathrm{S}$ & $\mathrm{S}$ & $\mathrm{S}$ & NS & $\mathrm{S}$ & NS \\
\hline $\mathbf{P} \times \mathbf{B} \times \mathbf{A M}$ & $\mathrm{S}$ & NS & S & NS & NS & S \\
\hline
\end{tabular}

P0 and P1 means phosphorus @ 0 and 50\% RDF respectively; NB, RHB, LB and PB means no biochar, rice husk biochar, lantana biochar and parthenium biochar@10 t ha ${ }^{-1}$ respectively; AM0 and AM1 means mycorrhiza @ 0 and $5 \mathrm{~g} \mathrm{pot}^{-1}$ respectively. $\mathrm{P} \times \mathrm{B}$ means phosphorus and biochar interaction, $\mathrm{P} \times \mathrm{AM}$ means phosphorus and mycorrhiza interaction, $\mathrm{B} \times \mathrm{AM}$ means biochar and mycorrhiza interaction, $\mathrm{P} \times \mathrm{B} \times \mathrm{AM}$ means phosphorus, biochar and mycorrhiza interaction. S means significance and NS means non significant. 
Table.2 Sulphur, zinc and iron uptake by cob and straw of baby corn as affected by different levels of phosphorus, biochar and AM

\begin{tabular}{|c|c|c|c|c|c|c|}
\hline \multirow[t]{2}{*}{ Treatment } & \multicolumn{2}{|c|}{ Sulphur uptake } & \multicolumn{2}{|c|}{ Zinc uptake } & \multicolumn{2}{|c|}{ Iron uptake } \\
\hline & $\begin{array}{c}\text { Cob } \\
\left(\mathrm{mg} \mathrm{pot}^{-1}\right)\end{array}$ & $\begin{array}{c}\text { Straw } \\
\left(\mathrm{mg} \mathrm{pot}^{-1}\right)\end{array}$ & $\begin{array}{c}\text { Cob } \\
\left(\mathrm{mg} \mathrm{pot}^{-1}\right)\end{array}$ & $\begin{array}{c}\text { Straw } \\
\left(\mathrm{mg} \mathrm{pot}^{-1}\right)\end{array}$ & $\begin{array}{c}\text { Cob } \\
\left(\mathrm{mg} \mathrm{pot}^{-1}\right)\end{array}$ & $\begin{array}{c}\text { Straw } \\
\left(\mathrm{mg} \mathrm{pot}^{-1}\right)\end{array}$ \\
\hline NB & 36.4 & 1006 & 0.42 & 18.2 & 1.22 & 80.6 \\
\hline RHB & 38.6 & 1077 & 0.46 & 20.0 & 1.26 & 85.4 \\
\hline PB & 43.3 & 1156 & 0.47 & 21.4 & 1.25 & 88.1 \\
\hline LB & 42.6 & 1263 & 0.49 & 21.6 & 1.28 & 87.6 \\
\hline SEm \pm & 0.68 & 20.4 & 0.01 & 0.48 & 0.01 & 0.31 \\
\hline $\mathrm{CD}(\mathrm{p} \leq \mathbf{0 . 0 5})$ & 1.95 & 59.0 & 0.03 & 1.39 & 0.04 & 0.90 \\
\hline P0 & 33.7 & 961.6 & 0.47 & 18.1 & 1.09 & 79.6 \\
\hline P1 & 46.8 & 1290 & 0.45 & 22.4 & 1.41 & 91.3 \\
\hline SEm \pm & 0.48 & 14.5 & 0.01 & 0.34 & 0.01 & 0.22 \\
\hline $\mathrm{CD}(\mathrm{p} \leq \mathbf{0 . 0 5})$ & 1.38 & 41.7 & 0.02 & 0.98 & 0.03 & 0.63 \\
\hline AM0 & 38.5 & 1054 & 0.45 & 16.1 & 1.13 & 81.9 \\
\hline AM1 & 41.9 & 1198 & 0.47 & 24.5 & 1.38 & 89.0 \\
\hline SEm \pm & 0.48 & 14.5 & 0.01 & 0.34 & 0.01 & 0.22 \\
\hline $\mathrm{CD}(\mathrm{p} \leq \mathbf{0 . 0 5})$ & 1.38 & 41.7 & 0.02 & 0.98 & 0.03 & 0.63 \\
\hline $\mathbf{P} \times \mathbf{B}$ & $\mathrm{S}$ & NS & $\mathrm{S}$ & $\mathrm{S}$ & NS & $\mathrm{S}$ \\
\hline $\mathbf{P} \times \mathbf{A} \mathbf{M}$ & NS & NS & S & $S$ & S & NS \\
\hline $\mathbf{B} \times \mathbf{A M}$ & NS & NS & NS & NS & NS & $\mathrm{S}$ \\
\hline $\mathbf{P} \times \mathbf{B} \times \mathbf{A M}$ & NS & NS & NS & NS & NS & $S$ \\
\hline
\end{tabular}

P0 and P1 means phosphorus @ 0 and 50\% RDF respectively; NB, RHB, LB and PB means no biochar, rice husk biochar, lantana biochar and parthenium biochar@10 t ha ${ }^{-1}$ respectively; AM0 and AM1 means mycorrhiza @0 and $5 \mathrm{~g} \mathrm{pot}^{-1}$ respectively. $\mathrm{P} \times \mathrm{B}$ means phosphorus and biochar interaction, $\mathrm{P} \times \mathrm{AM}$ means phosphorus and mycorrhiza interaction, $\mathrm{B} \times \mathrm{AM}$ means biochar and mycorrhiza interaction, $\mathrm{P} \times \mathrm{B} \times \mathrm{AM}$ means phosphorus, biochar and mycorrhiza interaction. S means significance and NS means non significant.

Potassium uptake by cob and straw of baby corn

From the data given in table 1, it has been found that application of $\mathrm{P} 1$ recorded the highest potassium uptake in cob and straw which exceeded P0 by $24.7 \%$ and $13.9 \%$. Effect of application of LB was significant in increasing the potassium uptake of cob and straw. Application of LB showed significantly higher potassium uptake in cob and straw and the values were higher by $3.54 \%$ and $8.5 \%$, respectively compared to NB. Lehmann et al., (2003) also reported that $\mathrm{K}$ uptake in plant increased with biochar application. The inoculation with AM recorded significant increase in potassium uptake by cob $(6.23 \%)$ and straw (6.97\%) over AM0. Significant interaction between phosphorus and biochar was observed for potassium uptake in cob and straw. The application of $\mathrm{LB}+\mathrm{P} 1$ showed higher potassium uptake in cob $(62.8 \mathrm{mg}$ pot $^{-1}$ ) over $\mathrm{NB}+\mathrm{P0}$ (49.1 $\mathrm{mg}$ pot $^{-1}$ ) and $\mathrm{RHB}+\mathrm{P} 1$ showed higher potassium uptake in straw (4.77 $\mathrm{g} \mathrm{pot}^{-1}$ ) over NB+P1 (3.76 g pot $\left.^{-1}\right)$. Significant interaction between phosphorus and mycorrhiza was observed for potassium uptake in cob and straw. The application of P1+AM1 showed higher potassium uptake in cob by (62.8 mppot $\left.^{-1}\right)$ and straw (4.87 $\mathrm{g} \mathrm{pot}^{-1}$ ) over P0+AM0 (47.4 $\mathrm{mg} \operatorname{pot}^{-1}$ ) and P0+AM0 (4.04 g pot $\left.^{-1}\right)$ respectively. Enhanced acquisition of $\mathrm{Ca}$ and $\mathrm{Mg}$ and usually $\mathrm{K}$ has been noted for various 
plants colonized with different arbuscular mycorrhizal fungi isolates compared to nonmycorrhizal plants (Siqueiraet al., 1990). Significant interaction among phosphorus, mycorrhiza and biochar was observed for potassium uptake in straw. The application of $\mathrm{PB}+\mathrm{P} 1+\mathrm{AM} 1$ showed higher potassium uptake in cob $\left(4.97 \mathrm{~g} \operatorname{pot}^{-1}\right)$ over $\mathrm{NB}+\mathrm{P} 0+\mathrm{AM} 0$ (3.56 $\left.\mathrm{g} \mathrm{pot}^{-1}\right)$. The biochar has ability to retain nutrients thereby reducing leaching resulting in increased nutrient uptake by plants and so higher production (Glaser $e t$ al., 2002).

\section{Sulphur uptake by cob and straw of baby corn}

Data presented in table 2 indicated that the application of AM1 resulted in significantly higher sulphur uptake of cob and straw and the increments were $8.82 \%$ and $13.7 \%$, respectively over AM0.For mycorrhiza treated maize grown in acidic soil, Glomus intraradices enhanced $\mathrm{S}$ acquisition over nonmycorrhiza treated plants more than Glomus etunicatum and Glomus diaphanum plants (Clark and Zeto, 1996). Glomus etunicatum inoculated switchgrass had 2-fold higher $S$ uptake than uninoculated switch grass (Clark et al., 1999). Effect of application of biochar was found to be significant on sulphur uptake of cob and straw. The application of P1 showed significantly higher sulphur uptake in cob and straw as compared to P0.Significant interaction between phosphorus and biochar was observed for sulphur uptake in cob only. The highest uptake of sulphur in cob was obtained with the application of LB+P1 (51 ppm) compared to $\mathrm{NB}+\mathrm{P} 0$ (30 ppm).

\section{Zinc uptake by cob and straw of baby corn}

A critical observation of the data given in table 2 indicates that the effect of phosphorus on zinc content in cob was non-significant.
Application of P1 significantly decreased $\mathrm{Zn}$ content in cob by $3.08 \%$ as compared with $\mathrm{P} 0$. Acquisition of $\mathrm{Zn}$ and $\mathrm{Cu}$ in shoots was reported to be reduced when $\mathrm{P}$ was increased in soil (Lambert and Weidensaul, 1991). Raju et al., (1990) found that enhanced acquisition of these nutrients occurred even at high levels of soil P. This may happen as phosphorus increased plant dry matter yield, so over all $\mathrm{Zn}$ uptake of straw also increased. Application of biochar increased the zinc uptake significantly over control. Application of LB showed significantly higher zinc uptake in cob and straw which exceeded NB by $17.3 \%$ and $18.5 \%$, respectively. Inoculation with AM1 significantly increased the zinc uptake in cob exceeding AM0 by $4.43 \%$. AM1 also significantly increased straw $\mathrm{Zn}$ uptake (24.5 mg/pot) as compared to no inoculation of AM (16 mg pot $\left.{ }^{-1}\right)$. Significant interaction between biochar and phosphorus was observed for zinc uptake in cob as well as in straw. The highest cob uptake of zinc was obtained with the application of LB+P1 (51.1 mg pot $^{-1}$ ) whereas the lowest zinc uptake was recorded with the treatment $\mathrm{NB}+\mathrm{P} 0(30.5 \mathrm{mg}$ $\left.\operatorname{pot}^{-1}\right)$. These findings are similar to those of Rondan et al., (2007) who have reported increase in zinc uptake increases with biochar addition in common beans as it increases the activity of rhizobacteria. Significant interaction between arbuscular mycorrhizal fungi and phosphorus was observed for zinc uptake in cob and straw both. Arbuscular mycorrhizal treatment without phosphorus increased cob $\mathrm{Zn}$ uptake $\left(0.50 \mathrm{mg}\right.$ pot $\left.^{-1}\right)$ in compare to the application of phosphorus $\left(0.45 \mathrm{mgpot}^{-1}\right)$. In case of straw, combined application of arbuscular mycorrhizal fungi and P1 had the advantage over no application of phosphorus and arbuscular mycorrhizal fungi. The contribution of hyphae to enhanced acquisition of $\mathrm{Zn}$ in Glomus mosseae maize was calculated to be $48 \%$ of the total plant $\mathrm{Zn}$ in one study (Kothari et al., 1991) and from 16 to $25 \%$ in another (Kothari et al., 1991). 
Compared to non mycorrhizal treated plants, root $\mathrm{Zn}$ was $22 \%$ higher in AM plants, indicating that $\mathrm{Zn}$ transport from hyphae to roots and from roots to shoots was enhanced (Kothari et al., 1991).

\section{Iron uptake by cob and straw of baby corn}

Data presented in table 2 indicated that iron uptake in coband straw with application of P1 was significantly higher by $28.9 \%$ and $14.6 \%$, respectively than that recorded with $\mathrm{P}$. Application of biochar significantly increased the iron uptake. Inoculation with AM1 significantly increased the iron uptake in cob and straw by $21.8 \%$ and $8.71 \%$, respectively over AM0. Significant interaction between mycorrhiza and phosphorus was observed for iron uptake by cob. Arbuscular mycorrhizal fungi with phosphorus application increased the cob Fe uptake (1.57 ggpot $\left.^{-1}\right)$ as compared to P0 $\left(1.0 \mathrm{mg} \operatorname{pot}^{-1}\right)$. Mycorrhizal treated plants grown in alkaline soil exhibited greater differences for $\mathrm{Fe}$ acquisition than those grown in acidic soil, and some arbuscular mycorrhizal fungi isolates were more effective in enhancing $\mathrm{Fe}$ acquisition than others (Clark and Zeto, 1996). Significant interaction between biochar and phosphorus was observed for iron uptake in straw. Combined application of $\mathrm{PB}+\mathrm{P} 1$ increased cob Fe uptake (92.8 $\mathrm{mg} \mathrm{pot}^{-1}$ ) as compared to $\mathrm{NB}+\mathrm{PO}\left(71.5 \mathrm{mgpot}^{-1}\right)$. Significant interaction between biochar and mycorrhiza was observed for iron uptake in straw. Combined application of PB+AM1 increased baby cob Fe uptake (921 mg pot $\left.{ }^{-1}\right)$ as compared to NB and AM0 $\left(76.2 \mathrm{mg} \operatorname{pot}^{-1}\right)$. Significant interaction among mycorrhiza, biochar and phosphorus was observed for iron uptake in straw. Combined application of PB+P1+AM1 increased cob Fe uptake $\left(96.8 \mathrm{mg}^{-1}\right.$ pot $\left.^{-1}\right)$ as compared to NB+P0+AM0 (66.5 mg pot $\left.{ }^{-1}\right)$. Iron acquisition has been associated with root exudation of substances like phytosiderophores (strategy II graminaceous plants) (Marschner and Römheld, 1994) and organic acids such as citric, oxalic, and phenolics (strategy I dicotyledonous plants) (Marschner, 1995).

In conclusion application of lantana biochar along with $50 \%$ recommended dose of phosphorus and arbuscular mycorrhizal inoculation was found to be most effective in enhancing the $\mathrm{N}, \mathrm{P}, \mathrm{K}, \mathrm{S}, \mathrm{Zn}$ and Fe uptake over other integrated treatments.

\section{References}

Bago, B., Vierheilig, H., Piché, Y., andAzcon- Aguilar, C. 1996. Nitrate depletion and $\mathrm{pH}$ changes induced by the extra radical mycelium of the arbuscular mycorrhizal fungus Glomus intraradices grown in monoxenic culture. New Phytologist, 133: 273-280.

Clark, R. B., and Zeto, S. K. 1996.Mineral acquisition by mycorrhizal maize grown on acid and alkaline soil. Soil Biology and Biochemistry, 28: 1495-1503.

Clark, R. B., Zeto, S. K., and Zobel, R. W. 1999. Arbuscularmycorrhizal fungal isolate effectiveness on growth and root colonization of Panicum virgatum in acidic soil. Soil Biology and Biochemistry, 31: 1757-1763.

George, E., Häussler, K. U., Vetterlein, D., Gorgus, E., and Marschner, H. 1992. Water and nutrient translocation by hyphae of Glomus mosseae. Canadian Journal of Botany, 70: 2130-2137.

Glaser, B., Lehmann, J., and Zech, W. 2002.Ameliorating physical and chemical properties of highly weathered soils in the tropics with charcoal-a review. Biology and fertility of soils, 35: 219-230.

Kothari, S. K., Marschner, H., and Römheld, V. 1991.Contribution of the VA mycorrhizal hyphae in acquisition of phosphorus and zinc by maize grown in 
a calcareous soil. Plant and soil, 131: 177-185.

Lambert, D. H., and Weidensaul, T. C. 1991.Element uptake by mycorrhizal soybean from sewage-sludge-treated soil. Soil Science Society of America Journal, 55: 393-398.

Lehmann, J., da Silva, J. P., Steiner, C., Nehls, T., Zech, W., and Glaser, B. 2003. Nutrient availability and leaching in an archaeological Anthrosol and a Ferralsol of the Central Amazon basin: fertilizer, manure and charcoal amendments. Plant and soil, 249: 343357.

Marschner, H. 1995. The soil root interface (rhizosphere) in relation to mineral nutrition. Mineral nutrition of higher plants.

Marschner, H., and Dell, B. 1994.Nutrient uptake in mycorrhizal symbiosis. Plant and soil, 159: 89-102.

Raju, P. S., Clark, R. B., Ellis, J. R., and Maranville, J. W. 1990. Mineral uptake and growth of sorghum colonized with VA mycorrhiza at varied soil phosphorus levels. Journal of plant nutrition, 13: 843-859.
Siqueira, J. O., Rocha, W. F., Oliveira, E., and Colozzi-Filho, A. 1990. The relationship between vesiculararbuscular mycorrhiza and lime: associated effects on the growth and nutrition of brachiaria grass (Brachiaria decumbens). Biology and fertility of soils, 10: 65-71.

Subramanian, K. S., and Charest, C. 1998. Arbuscularmycorrhizae and nitrogen assimilation in maize after drought and recovery. Physiologia plantarum, 102: 285-296.

Tandon, H.L.S. 2001.Methods of analysis of soils, plants, waters, and fertilizers. Fertilizer Development and Consultation Organization, New Delhi, India.

Tinker, P. B., Jones, M. D., and Durall, D. M. 1992.A functional comparison of ectoand endomycorrhizas. Mycorrhizas in ecosystems, 303-310.

Zwetsloot, M. J., Lehmann, J., Bauerle, T., Vanek, S., Hestrin, R., and Nigussie, A. 2016. Phosphorus availability from bone char in a P-fixing soil influenced by root-mycorrhizae-biochar interactions. Plant and soil, 408: 95105.

\section{How to cite this article:}

Arghya Chattopadhyay, A.P. Singh, Sumit Rai, Awtar Singh and Ajoy Das. 2017. Improving Acquisition of Phosphorus and Other Nutrient Elements by Baby Corn (Zea mays L.) through the Combine Use of Biochar, Phosphorus and Arbuscular Mycorrhiza. Int.J.Curr.Microbiol.App.Sci. 6(11): 1319-1326. doi: https://doi.org/10.20546/ijcmas.2017.611.158 